\title{
Condroma intramuscular extraesquelético do joelho - Relato de caso e revisão da literatura*
}

\section{Extraskeletal Intramuscular Chondroma of the Knee - Case Report and Review of the Literature}

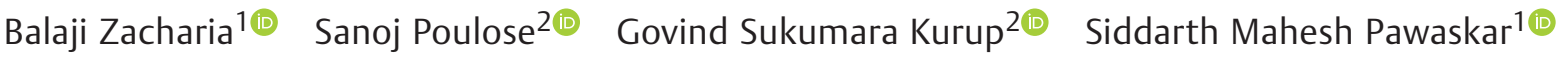 \\ ${ }^{1}$ Departamento de Ortopedia, Government Medical College, \\ Kozhikkode, Kerala, Índia \\ ${ }^{2}$ Departamento de Ortopedia, Jubilee Mission Medical College,

\begin{abstract}
Endereço para correspondência Balaji Zacharia, MBBS, Department of Orthopedics, Govt. Medical College, Kozhikkode, Kerala 673008, India (e-mail: balaji.zacharia@gmail.com).
\end{abstract} Trichur, Kerala, Índia

Rev Bras Ortop

\section{Resumo \\ Palavras-chave \\ - condroma \\ - condromatose sinovial \\ - joelho \\ - neoplasias de tecidos moles}

Os condromas extraesqueléticos são pequenas lesões cartilaginosas nodulares que não estão aderidas ao osso ou ao periósteo. São tumores raros que ocorrem comumente nas mãos e nos pés. Objetivo deste artigo é descrever um caso de condroma intramuscular extraesquelético (CIE) no joelho esquerdo e os desafios diagnósticos que enfrentamos.

Uma paciente de 25 anos apresentou um edema de crescimento lento no joelho esquerdo havia 2 anos. Clinicamente, o edema era proveniente do músculo quadríceps. Foram consideradas possibilidades como rabdomioma, neurofibroma, e lipoma intramuscular. Os estudos de imagem sugeriram um tumor de gordura benigno. A paciente foi tratada com a excisão cirúrgica. A microscopia indicou CIE sem recorrência.

O CIE é uma lesão rara. Clinicamente, pode ter aspecto semelhante ao de outros tumores benignos dos tecidos moles. A histopatologia pode fornecer um diagnóstico definitivo. A excisão cirúrgica do tumor é curativa.

Extraskeletal chondromas are small nodular cartilaginous lesions not attached to bone or the periosteum. They are rare tumors commonly occurring in the hands and feet. The objective of the present study is to describe a case of extraskeletal intramuscular chondroma (EIC) in the left knee and the diagnostic challenges faced by us.

A 25-year-old female patient presented with slow-growing swelling in the left knee for 2 years. Clinically, the swelling was arising from the quadriceps muscle. We considered possibilities such as rhabdomyoma, neurofibroma, and intramuscular lipoma. Imaging studies suggested a benign fatty tumor. She was treated by excision. Microscopy was consistent with EIC without recurrence.

A rare entity, clinically, EIC can mimic other benign soft-tissue tumors. Histopathology exams can provide a definitive diagnosis. The excision of the tumor is curative.

Trabalho desenvolvido no Departamento de Ortopedia, Jubilee Mission Medical College, Trichur, Kerala, Índia

recebido

31 de Janeiro de 2021

aceito

07 de Abril de 2021
DOI https://doi.org/

10.1055/s-0041-1731796.

ISSN 0102-3616. (c) 2021. Sociedade Brasileira de Ortopedia e Traumatologia. All rights reserved.

This is an open access article published by Thieme under the terms of the Creative Commons Attribution-NonDerivative-NonCommercial-License, permitting copying and reproduction so long as the original work is given appropriate credit. Contents may not be used for commercial purposes, or adapted, remixed, transformed or built upon. (https://creativecommons.org/ licenses/by-nc-nd/4.0/)

Thieme Revinter Publicações Ltda., Rua do Matoso 170, Rio de Janeiro, RJ, CEP 20270-135, Brazil 


\section{Introdução}

Os condromas de tecidos moles são pequenas lesões nodulares bem definidas da cartilagem que não estão aderidas ao osso ou ao periósteo. Eles também são conhecidos como condromas intramusculares extraesqueléticos (CIEs). Descritos pela primeira vez por Baumuller (1883). ${ }^{1}$ sua incidência é de $\sim 1,5 \%$ dos tumores benignos de tecidos moles.

Eles ocorrem entrem a segunda e a sétima décadas de vida, com predominância na terceira e quarta décadas. ${ }^{2}$ São tumores de crescimento lento com predomínio no sexo masculino. As mãos e os pés são os locais mais acometidos. Eles se manifestam como nódulos dolorosos e crescentes. ${ }^{3}$

O CIE é raro na extremidade inferior, e o pé é o sítio mais comum. A coxa, a região poplítea, o joelho e a perna são raramente acometidos. ${ }^{4}$ Neste artigo, descrevemos um caso de CIE no joelho esquerdo de uma paciente de 25 anos.

\section{Relato de Caso}

Uma dona de casa de 25 anos observou um edema indolor na face interna do joelho esquerdo havia 2 anos, que aumentava de tamanho lentamente. Ela não apresentava febre, sintomas constitucionais, ou trauma. Suas atividades cotidianas não foram afetadas. Havia um edema oval indolor (que media $8 \mathrm{~cm} \times 5 \mathrm{~cm} \times 4 \mathrm{~cm}$ ) na face anteromedial da articulação do joelho esquerdo. Não havia características de inflamação local. O inchaço apresentava superfícies lisas, bordas regulares, margens bem definidas, e consistência firme, e tinha como origem o músculo quadríceps subjacente. Os movimentos da articulação do joelho estavam normais, sem déficits neurovasculares distais ou linfonodomegalia local. Foram considerados como diagnósticos diferenciais rabdomioma, neurofibroma, lipoma intramuscular e edema bursal.

O hemograma, a velocidade de hemossedimentação (VHS) e os níveis de proteína $C$ reativa estavam dentro dos valores de referência. A radiografia da articulação do joelho esquerdo evidenciou lesão de tecidos moles na face anteromedial, com múltiplas calcificações (-Fig. 1). A ressonância magnética do joelho esquerdo mostrou uma grande massa de tecido mole que media $6,6 \mathrm{~cm} \times 5 \mathrm{~cm} \times 3,7 \mathrm{~cm}$, e tinha como origem o músculo vasto medial no compartimento anterior da coxa esquerda. Havia áreas com intensidade de sinal semelhante à da gordura subcutânea, e áreas com calcificação distrófica dentro da lesão. A cavidade articular e a sinóvia não foram afetadas. A gordura subcutânea adjacente e o músculo apresentavam aparência normal, sem alterações inflamatórias circundantes (-Fig. 2). Os diagnósticos diferenciais foram lipoma condroide, lipossarcoma bem diferenciado, e tumores de gordura malignos.

Por meio de uma incisão em $S$ aberto (lazy $S$, em inglês) com $10 \mathrm{~cm}$ de comprimento sobre o edema, foram abertos a pele e os tecidos subcutâneos. Foi realizada a excisão do edema, incluindo um manguito do músculo normal. 0 edema era proveniente do músculo vasto medial, com uma pseudocápsula (-Fig. $\mathbf{3}$ ).
Macroscopicamente, o edema era uma massa nodular bem circunscrita. O tamanho era de $7 \mathrm{~cm} \times 4 \mathrm{~cm} \times 4 \mathrm{~cm}$, com os músculos aderidos (-Fig. 4). A seção do corte era brancoacinzentada e amarelada, com áreas de consistência arenosa e mixoide, e os músculos estavam normais. Microscopicamente, o tumor era composto por nódulos de cartilagem hialina madura, com espaços lacunares com condrócitos. Alguns condrócitos apresentavam calcificação em renda. Os tecidos cartilaginosos estavam separados por tecido fibromixoide frouxo e tecido adiposo. As áreas focais de ossificação eram evidentes. Não havia evidência de atipia celular, mitose ou necrose. As margens ressecadas mostravam músculos esqueléticos normais (-Fig.5). O diagnóstico histopatológico foi CIE.

$\mathrm{O}$ período pós-operatório foi sem intercorrências. As suturas foram retiradas no décimo dia. A paciente ficou assintomática depois disso. Não houve recorrência após 3 anos de acompanhamento. Obtivemos o consentimento para publicar este relatório.

\section{Discussão}

Os CIEs são tumores extremamente raros dos tecidos moles que surgem sem ligação direta ao osso ou à sinóvia. Há controvérsia quanto à origem. Alguns autores consideram que eles se originam da sinóvia, ao passo que outros os consideram uma falha de desenvolvimento ou uma metaplasia. A transformação maligna raramente é relatada. Há

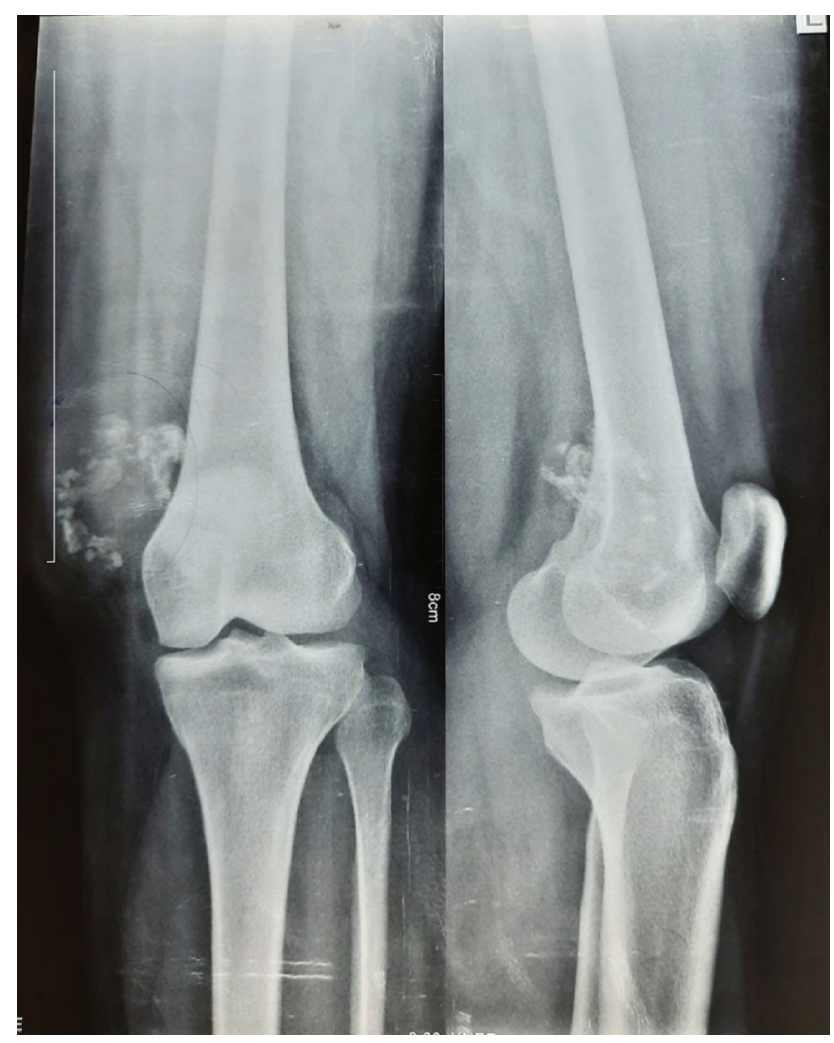

Fig. 1 Radiografia de uma paciente de 25 anos com edema de crescimento lento no joelho esquerdo que evidencia lesão de tecidos moles na face anteromedial com múltiplas calcificações puntiformes e circulares. 


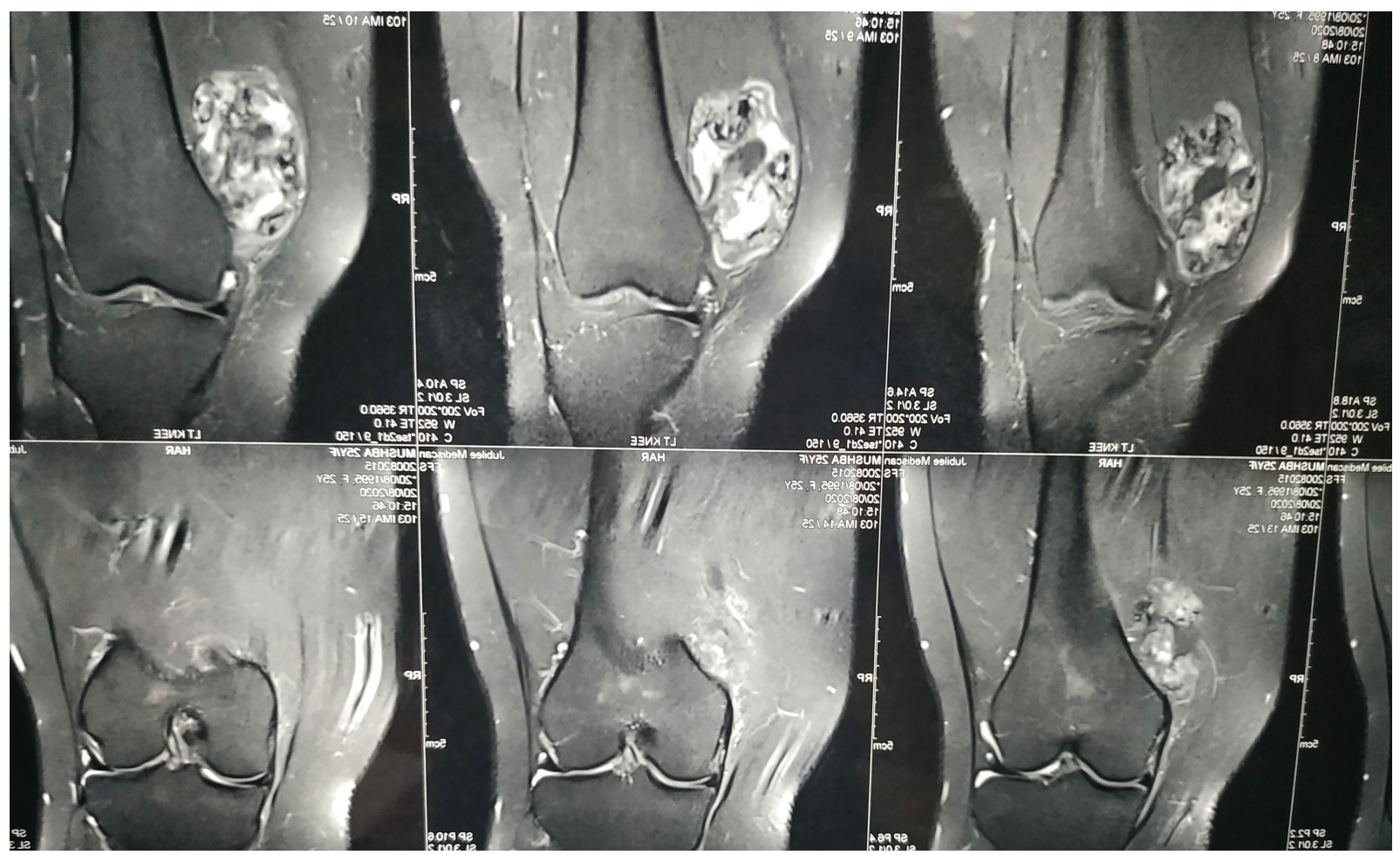

Fig. 2 A ressonância magnética da paciente mostra uma grande massa nos tecidos moles, medindo $6,6 \mathrm{~cm} \times 5 \mathrm{~cm} \times 3,7 \mathrm{~cm}$, e tendo como origem o músculo vasto medial no compartimento anterior da coxa esquerda. A lesão apresenta áreas com intensidade de sinal semelhante à da gordura subcutânea, com nódulos nos tecidos moles. Havia áreas de calcificação distrófica dentro da lesão. A cavidade articular e a sinóvia não foram afetadas.

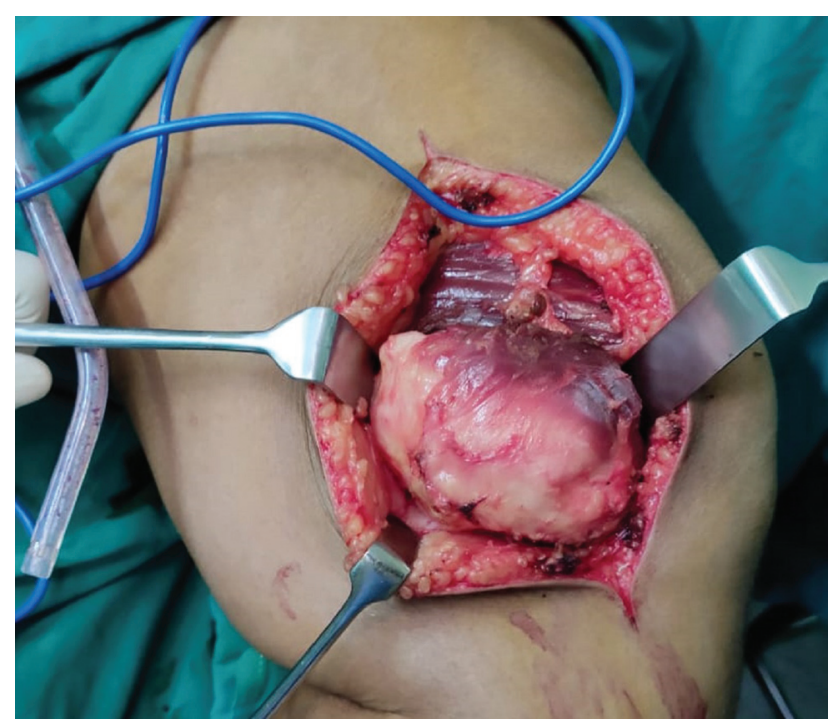

Fig. 3 Imagem intraoperatória mostrando edema nos tecidos moles de $7 \mathrm{~cm} \times 4 \mathrm{~cm} \times 4 \mathrm{~cm}$, tendo como origem o músculo vasto medial, com pseudocápsula. Não houve infiltração nos tecidos moles ou ossos circundantes.

relatos de predomínio masculino e feminino, e os CIEs são vistos perto dos tendões e bainhas dos tendões. ${ }^{3}$

Radiograficamente, a calcificação é evidente em 33\% a 77\% dos casos. Os padrões usuais de calcificação incluem os tipos curvilíneos, puntiformes, e os que são um misto de curvilíneo e puntiforme. A ressonância magnética mostra hipointensidade uniforme, com imagens ponderadas em T1 e T2 com

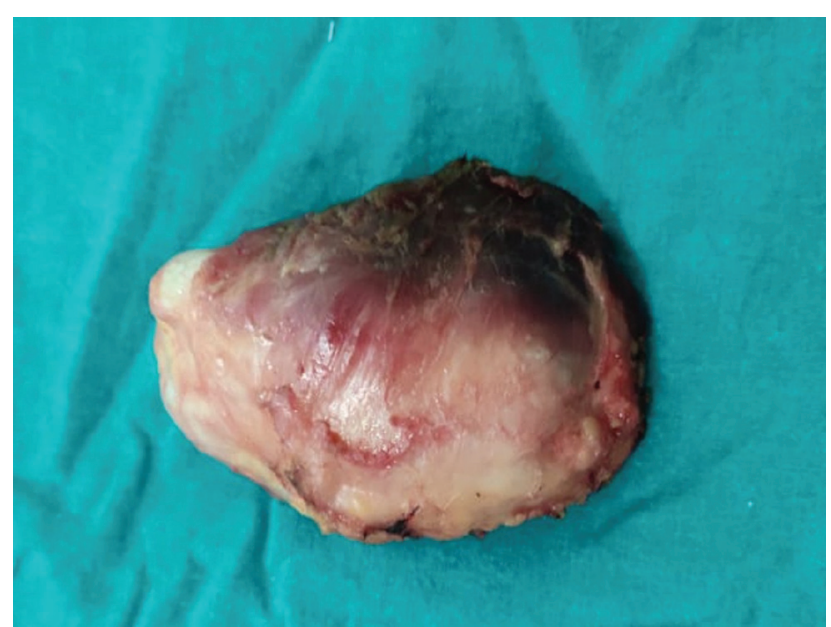

Fig. 4 Imagem da amostra ressecada.

áreas de calcificação homogênea ou distrófica. Os diagnósticos diferenciais radiográficos são condromatose sinovial, mesênquimoma, corpos livres, condroma periosteal, miosite ossificante, doenças por depósito de cristais, sarcoma sinovial, e condrossarcoma maligno de tecidos moles. ${ }^{5}$ Histopatologicamente, são tumores altamente celulares, com pleomorfismo nuclear leve a moderado e mitose dispersa. São observadas áreas de fibrose focal, ossificação, e alterações mixomatosas. Raramente são relatadas células gigantes semelhantes aos osteoclastos e às células epitelioides, com proliferação semelhante à do granuloma. ${ }^{6}$ Foram relatados 


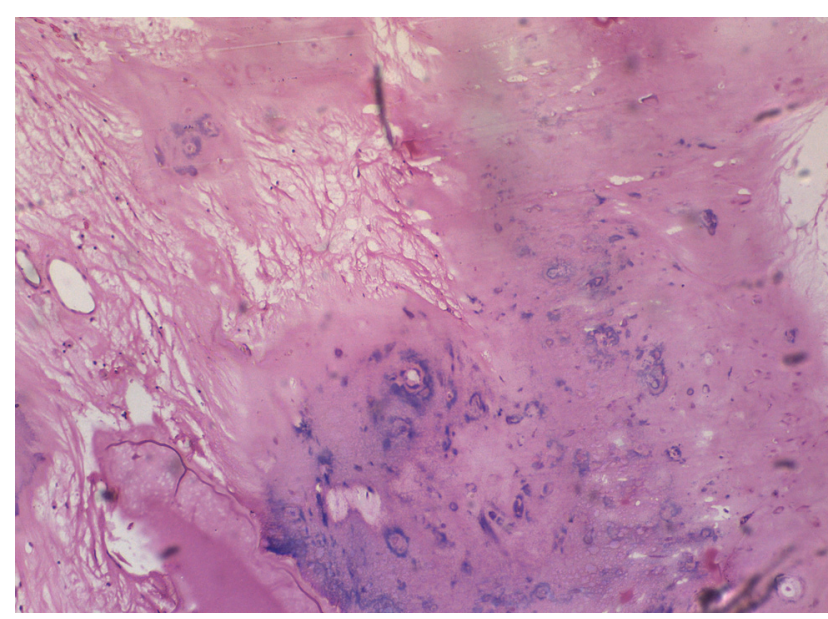

Fig. 5 Microscopia da amostra ressecada evidenciando nódulos da cartilagem hialina madura, com espaços lacunares com condrócitos. Alguns condrócitos apresentam calcificação em renda. Os tecidos cartilaginosos são separados por tecido fibromixoide frouxo e tecido adiposo. São evidenciadas áreas focais de ossificação. Não havia evidência de atipia celular, mitose ou necrose. As margens ressecadas mostram músculos esqueléticos normais.

cromossomos em anel supranumerários de diferentes tamanhos e números em um caso de condroma de tecido mole. ${ }^{7}$

Essas lesões são comuns nas mãos e nos pés. Os condromas de tecidos moles foram relatados no músculo masseter, na língua, na faringe, na laringe, e eoutras partes da região da cabeça e do pescoço. ${ }^{8}$ O CIE pode causar dedos em gatilho, sintomas semelhantes à fascite plantar, e doença de Hoffa. ${ }^{9}$ Houve outro relato de paralisia do nervo interósseo posterior em virtude de compressão por um condroma de tecidos moles. A excisão da lesão é curativa. Raramente é relatada recorrência. $^{10}$

Este relato de caso é o de uma paciente de 25 anos com edema na face anteromedial do joelho esquerdo. IClinicamente, foram consideradas possibilidades como rabdomioma, fibroma, neurofibroma, e bursa. A lesão era no músculo quadríceps, e o movimento do joelho se mostrava restringido com a contração do músculo. A evolução lenta e a ausência de muitos sintomas nos levaram a considerar o diagnóstico de rabdomioma ou um lipoma intramuscular. Devido à presença de tecido adiposo e calcificações na ressonância magnética, o diagnóstico radiológico foi de tumor lipomatoso benigno. Porém, para nossa surpresa, o diagnóstico microscópico foi condroma extraesque- lético de tecidos moles. Este caso foi apresentado para destacar a raridade desta condição e descrever os desafios clínicos e investigativos enfrentados.

O CIE é uma lesão rara. Clinicamente, pode ser semelhante a outros tumores benignos de tecidos moles. A histopatologia pode fornecer um diagnóstico definitivo. A excisão cirúrgica do tumor é curativa.

\section{Suporte Financeiro}

Não houve suporte financeiro de fontes públicas, comerciais, ou sem fins lucrativos.

\section{Conflito de Interesses}

Os autores declaram não haver conflito de interesses.

\section{Referências}

1 Kransdorf MJ, Meis JM. From the archives of the AFIP. Extraskeletal osseous and cartilaginous tumors of the extremities. Radiographics 1993;13(04):853-884

2 Bahnassy M, Abdul-Khalik H. Soft tissue chondroma: a case report and literature review. Oman Med J 2009;24(04):296-299

3 Zlatkin MB, Lander PH, Begin LR, Hadjipavlou A. Soft-tissue chondromas. AJR Am J Roentgenol 1985;144(06):1263-1267

4 Cardia R, Favazzi CM, Fenga D, Rosa MA, Ieni A. A Large Extraskeletal Chondroma: An Unusual Location in the Lower Extremity, Huge Extraskeletal Chondroma: An Unusual Localization in the Leg. J Orthop Case Rep 2019;9(01):74-77

5 Bansal M, Goldman AB, DiCarlo EF, McCormack R. Soft tissue chondromas: diagnosis and differential diagnosis. Skeletal Radiol 1993;22(05):309-315

6 Hondar $\mathrm{Wu} \mathrm{HT}$, Chen W, Lee O, Chang CY. Imaging and pathological correlation of soft-tissue chondroma: a serial five-case study and literature review. Clin Imaging 2006;30 (01):32-36

7 Shadan FF, Mascarello JT, Newbury RO, Dennis T, Spallone P, Stock AD. Supernumerary ring chromosomes derived from the long arm of chromosome 12 as the primary cytogenetic anomaly in a rare soft tissue chondroma. Cancer Genet Cytogenet 2000;118(02): 144-147

8 Vescovi P, Meleti M, Merigo E, et al. Soft Tissue Chondrome of the Oral Cavity: an extremely rare tumour localized on the hard palate. Case Rep Med 2014:1-5. Doi: 10;1155/2014/414861

9 Ingabire MI, Deprez FC, Bodart A, Puttemans T. Soft tissue chondroma of Hoffa's fat pad. JBR-BTR 2012;95(01):15-17

10 De Smet L. Posterior interosseous neuropathy due to compression by a soft tissue chondroma of the elbow. Acta Neurol Belg 2005; 105(02):86-88 